\title{
Endothelial-specific deletion of autophagy-related 7 (ATG7) attenuates arterial thrombosis in mice
}

\author{
Jonathan W. Yau, PhD, ${ }^{a}$ Krishna K. Singh, PhD, ${ }^{\text {a,b,e,f,g }}$ Yan Hou, MD, ${ }^{\text {a Xi Lei, MSc, }}{ }^{\text {d }}$ \\ Azza Ramadan, MSc, ${ }^{\mathrm{a}, \mathrm{f}}$ Adrian Quan, MPhil, ${ }^{\mathrm{a}}$ Hwee Teoh, PhD, ${ }^{\mathrm{a}, \mathrm{c}}$ \\ Wolfgang M. Kuebler, MD, Dr Med, ${ }_{\mathrm{e}, \mathrm{f}, \mathrm{g}, \mathrm{h}, \mathrm{l}}$ Mohammed Al-Omran, MD, MSc, ,e,f,g,m \\ Bobby Yanagawa, MD, PhD, ${ }^{\mathrm{a}, \mathrm{e}, \mathrm{g}}$ Heyu Ni, MD, PhD, ${ }^{\mathrm{d}, \mathrm{h}, \mathrm{i}, \mathrm{j}}$ and Subodh Verma, MD, $\mathrm{PhD}^{\mathrm{a}, \mathrm{e}, \mathrm{f}, \mathrm{g}, \mathrm{k}}$
}

\begin{abstract}
Background: Thrombosis persists as a leading cause of morbidity and mortality. Given that endothelial cells (ECs) play a central role in regulating thrombosis, understanding the molecular endothelial cues that regulate susceptibility or resistance to thrombosis have important translational implications. Accordingly, we evaluated the role of endothelial autophagy in the development of thrombosis.

Methods: We generated mice in which the essential autophagy-related 7 (ATG7) gene was conditionally deleted from ECs (EC-ATG7 $7^{-l-}$ mice). Three in vivo models of thrombosis were used, and mechanistic studies were conducted with cultured human umbilical vein endothelial cells (HUVECs).
\end{abstract}

Results: We silenced ATG7 in HUVECs and observed $>60 \%$ decreases in tumor necrosis factor (TNF)- $\alpha$-induced tissue factor (TF) transcript levels, protein expression, and activity. TF mRNA levels in the carotid arteries of EC-ATG7 $7^{-l-}$ mice subjected to the prothrombotic stimulus $\mathrm{FeCl}_{3}$ were lower than those in the similarly treated wild-type (WT) littermate group. Compared with WT mice, EC-ATG7 ${ }^{-1-}$ mice exhibited prolonged time to carotid (2-fold greater) and mesenteric (1.3-fold greater) artery occlusion following $\mathrm{FeCl}_{3}$ injury. The thrombi generated in laser-injured cremasteric arterioles were smaller in EC-ATG7 ${ }^{-1-}$ mice compared with WT mice, and took 2.3-fold longer to appear.

Conclusions: Taken together, these results provide definitive evidence that loss of endothelial ATG7 attenuates thrombosis and reduces the expression of TF. Our findings demonstrate that endothelial ATG7, and thus autophagy, is a critical and previously unrecognized target for modulating the susceptibility to thrombosis. (J Thorac Cardiovasc Surg 2017;154:978-88)

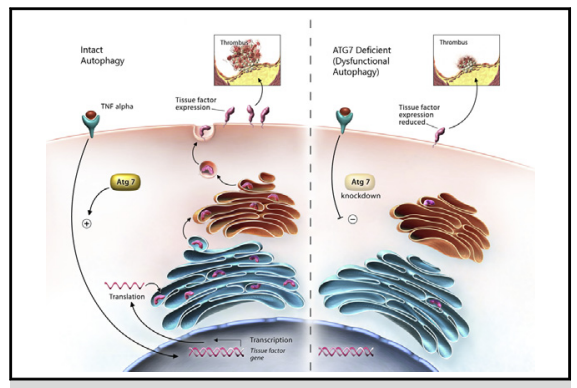

Role of ATG7 in the regulation of tissue factor expression and thrombus formation in ECs.

\section{Central Message}

Endothelial-specific deletion of ATG7 in mice attenuates thrombosis and reduces tissue factor expression. Endothelial autophagy is a novel target for reducing arterial and venous thromboses.

\section{Perspective}

Atherothrombosis can culminate in myocardial infarction and stroke. Recent evidence suggests that autophagy, an evolutionary conserved process that promotes cell survival in response to stress, occurs in platelets and endothelial cells, both of which are essential components for blood coagulation. Autophagy may contribute to the development of thrombosis and represents a novel target for antithrombotic therapy.

See Editorial Commentary page 989.
The endothelium serves as a barrier between the blood and surrounding vascular smooth muscle cells and contributes to the maintenance of blood fluidity. Endothelial dysfunction can lead to life-threatening thrombosis, which can occur in both native arteries and veins, as well as in vascular conduits and grafts. Arterial thrombosis leading to myocardial infarction and stroke, and venous thromboembolism leading to deep vein thrombosis and pulmonary embolism, are common and often fatal cardiovascular complications. $^{1,2}$ At the molecular level, endothelial cells (ECs)
From the Divisions of ${ }^{a}$ Cardiac Surgery, ${ }^{b}$ Vascular Surgery, and ${ }^{c}$ Endocrinology and Metabolism and Departments of ${ }^{\mathrm{d}}$ Laboratory Medicine and ${ }^{\mathrm{e}}$ Surgery, Keenan Research Centre for Biomedical Science, St. Michael's Hospital; ${ }^{\mathrm{f}}$ Institute of Medical Science and Departments of ${ }^{\mathrm{g}}$ Surgery, ${ }^{\mathrm{h}}$ Physiology, ${ }^{\mathrm{i}}$ Laboratory Medicine and Pathobiology, ${ }^{\mathrm{j}}$ Medicine, and ${ }^{\mathrm{k}}$ Pharmacology and Toxicology, University of Toronto, Toronto, Ontario, Canada; ${ }^{1}$ Institute of Physiology, Charité-Universitätsmedizin Berlin, Berlin, Germany; and ${ }^{\mathrm{m}}$ Department of Surgery, King Saud University and the King Saud University-Li Ka Shing Collaborative Research Program, Riyadh, Kingdom of Saudi Arabia.

This research was supported in part by a Fellowship from the Canadian Institute for Health Research (FRN 140815) to J.W.Y. and grants from the Heart and Stroke Foundation of Canada (G-13-0003003) and Canadian Institute for Health Research (142483) to S.V. J.W.Y. was the recipient of an EOCI-St. Michael's Hospital
Scholarship Award in Cardiometabolic Disease and Atherothrombosis. S.V. is the Canada Research Chair in Atherosclerosis at the University of Toronto.

Received for publication Aug 2, 2016; revisions received Feb 1, 2017; accepted for publication Feb 17, 2017; available ahead of print April 8, 2017.

Address for reprints: Subodh Verma, MD, PhD, Division of Cardiac Surgery, St. Michael's Hospital, Suite 8-003, Bond Wing, 30 Bond St, Toronto, Ontario M5B 1W8, Canada (E-mail: vermasu@smh.ca). or Krishna K. Singh, PhD, Division of Vascular Surgery, St. Michael's Hospital, 209 Victoria St, Toronto, Ontario M5B 1T8, Canada (E-mail: singhk@smh.ca).

$0022-5223 / \$ 36.00$

Copyright (C) 2017 by The American Association for Thoracic Surgery

http://dx.doi.org/10.1016/j.jtcvs.2017.02.058 


$$
\begin{aligned}
& \text { Abbreviations and Acronyms } \\
& \begin{aligned}
\text { ATG7 } & =\text { autophagy-related } 7 \\
\text { EC } & =\text { endothelial cell } \\
\text { HUVEC } & =\text { human umbilical vein endothelial cell } \\
\text { siRNA } & =\text { small interfering RNA } \\
\text { TF } & =\text { tissue factor } \\
\text { TNF } & =\text { tumor necrosis factor } \\
\text { WT } & =\text { wild type }
\end{aligned}
\end{aligned}
$$

Scanning this QR code will take you to a supplemental table and video for the article.

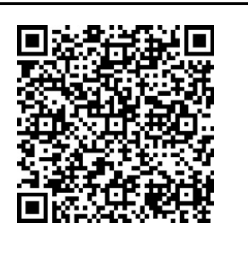

serve as an active barrier to prevent thrombosis. On vascular injury, ECs become activated and trigger intracellular signaling pathways, which in turn up-regulate procoagulant molecules, such as tissue factor (TF), and down-regulate anticoagulant molecules. These events result in the recruitment of platelets and formation of a fibrin mesh, both of which are the key cellular and protein components of the clot. Because of its location, the endothelium plays a key role in the initiation of thrombosis, highlighting the importance of EC regulation for the prevention of thrombosis.

Autophagy is a conserved and complex intracellular process that is essential for cellular homeostasis and also provides a survival mechanism for cells during stress. ${ }^{3-18}$ Whereas loss of autophagy has been implicated in the development of cancer and angiogenesis, ${ }^{3-8}$ enhanced autophagy has been implicated in life span extension. ${ }^{18}$ Of the 3 major groups of autophagy, macroautophagy (hereinafter autophagy) is the most widely studied. Autophagy involves a sequential process that results in the degradation of cellular material, such as proteins, lipids, and damaged organelles, inside double-membrane vesicles called autophagosomes. These autophagosomes fuse with lysosomes to form autolysosomes, where waste elimination, energy production, and recycling of cellular components occur.

Although the molecular mechanisms of autophagy were initially characterized in yeast, ${ }^{19}$ the process of autophagy is conserved across various species. The molecular signaling pathways regulating autophagy are complex. ${ }^{4}$ Nutrient starvation-induced mechanistic target of rapamycin inhibition leads to formation of the ATG1/Ulk1 protein kinase autophagy regulatory complex, which signals autophagic induction via initiation of a double-membranous phagophore formation. ${ }^{20}$ Expansion of the phagophore is mediated by 2 ubiquitin-like conjugation pathways, ${ }^{20}$ both of which involve the E1 ubiquitin-activating enzyme autophagy-related 7 (ATG7). ${ }^{21}$ In the first pathway, ATG12 conjugates with ATG5 through reactions of ATG7 and the E2 ubiquitin-conjugating enzyme ATG10. In the second, a microtubule-associated protein light chain 3 (LC3) is synthesized and immediately cleaved by ATG4 to produce an active cytosolic form, LC3-I. ATG7 and E2-conjugating enzyme ATG3 subsequently tag phosphatidylethanolamine to LC3-I to yield LC3-II, a critical step in autophagosome formation. The fusion of autophagosomes with lysosomes causes the inner membranes to lyse, releasing lysosomal hydrolases that go on to break down the autophagosomal content. The resultant macromolecules are released back into the cytosol for reuse. ${ }^{20}$

The critical role of ATG7 in autophagy is highlighted by the observation that mice lacking ATG7 die within 24 hours of birth. ${ }^{22}$ To circumvent the mortality associated with systemic loss of ATG7, many investigators have used strategies involving tissue-specific deletion of ATG7. Targeted deletion of $A T G 7$ in the hematopoietic system results in loss of hematopoietic stem cell function, severe myeloproliferation, and death within weeks. ${ }^{23}$ Likewise, conditional deletion of $A T G 7$ in the brain, skeletal muscle, hypothalamic neurons, and pancreas leads to marked alterations in tissue homeostasis, muscle mass, energy balance, diabetes, and early mortality, respectively. ${ }^{24-28}$ In the cardiovascular setting, EC-specific ATG7 knockout mice have been used to study atherosclerosis and fibrosis. ${ }^{29,30}$

Aside from nutrient starvation, which is a wellrecognized trigger of autophagy in the cardiovascular system, established cardiovascular risk factors, including age, hyperglycemia, hypertension, and smoking, as well as plaque-associated components, such as lipid peroxides and $\beta$-amyloid, also have been identified as stimulants of smooth muscle and endothelial autophagy. ${ }^{5}$

Impaired autophagic flux, a measure of autophagic degradation activity, has been reported in ischemia/reperfusion (I/R) damage, heart failure, and atherosclerosis ${ }^{4,5}$ but it is worth noting that autophagy can be beneficial in certain circumstances, specifically in EC regulation, angiogenesis, and atherosclerosis. ${ }^{4,5}$ Indeed, preclinical data support the idea that endothelial autophagy protects against endothelial inflammation and oxidative stress, as well as their associated cell death pathways. ${ }^{31-34}$ Curiously, although autophagy has been extensively studied in the progression of cardiovascular disease, its role in the development of thrombosis remains unclear. Ouseph and colleagues ${ }^{35}$ found that platelets exhibit autophagy machinery, and that megakaryocyte- and plateletspecific gene deletion of $A T G 7$ in mice is accompanied by a prolonged time to carotid artery occlusion after $\mathrm{FeCl}_{3}$ induced injury. Torisu and coworkers ${ }^{36}$ demonstrated that ECs also possess autophagic machinery, including ATG7, and that dysfunction of endothelial autophagy may decrease 
the secretion of von Willebrand factor. In the present study, we used a comprehensive combination of in vitro assays and in vivo murine models of thrombosis to provide definitive evidence as to which endothelial autophagy modulates the prothrombotic response.

\section{METHODS \\ Cell Culture}

Human umbilical vein ECs (HUVECs; Lonza, Basel, Switzerland) were grown in EC growth medium 2 (Bulletkit; Lonza) supplemented with growth factors, serum, and antibiotics at $37^{\circ} \mathrm{C}$ and $5 \% \mathrm{CO}_{2}$. ATG7 gene knockdown studies were performed with small interfering RNA (siRNA)-mediated deletion of ATG7 (siATG7) or nonspecific, scrambled siRNA control (Ambion, Austin, Tex) and Dharmafect-1 transfection reagent (GE Healthcare Dharmacon, Lafayette, Colo) in accordance with the manufacturer's guidelines. ECs were activated by treatment with recombinant human tumor necrosis factor- $\alpha$ (TNF- $\alpha$; Sigma-Aldrich, St. Louis, Mo) at a final concentration of $20 \mathrm{ng} / \mathrm{mL}$.

\section{Quantitative Real-Time PCR}

Total RNA from HUVECs was extracted with the RNeasy Mini Plus Kit (Qiagen, Germantown, Md). Total RNA from mouse carotid arteries was extracted with TRIzol reagent (Life Technologies, Grand Island, NY) and precipitated with isopropanol. Complementary DNA from total RNA was synthesized with the Quantitect kit (Qiagen) and subjected to quantitative RNA polymerase chain reaction (qPCR) with the StepOnePlus RealTime PCR System (Applied Biosystems, Foster City, Calif). In brief, SYBR Select Master Mix (Applied Biosystems) was mixed with $10 \mu \mathrm{M}$ forward and $10 \mu \mathrm{M}$ reverse primers according to the manufacturer's instructions. Human $A T G 7, T F$, and $G A P D H$ primers were used with samples from HUVECs, and mouse $A T G 7, T F$, and $G A P D H$ were used with those from mouse carotid arteries. Table E1 provides the complete sequences for the primers used for qPCR analysis. Data were analyzed with the manufacturer's integrated web-based software package.

\section{Immunoblotting}

Transfected HUVECs were lysed with RIPA buffer (Sigma-Aldrich) containing protease inhibitors (Complete Mini Protease Inhibitor Cocktail; Roche, Basel, Switzerland) and centrifuged at $12,000 \times g$ for 20 minutes at $4^{\circ} \mathrm{C}$. The supernatants were collected, and protein concentrations were determined with the BCA Protein Assay Kit (Pierce Biotechnology, Rockford, Ill). Equal amounts of protein $(50 \mu \mathrm{g})$ were loaded into $4 \%$ to $15 \%$ polyacrylamide gels (Bio-Rad, Hercules, Calif) under reducing conditions and transferred to nitrocellulose membranes (Amersham/GE Healthcare Biosciences, Pittsburgh, Pa). Proteins were detected by immunoblot analysis using polyclonal antibodies specifically directed against ATG7 (catalog no. 2631; Cell Signaling Technology, Danvers, Mass), TF (catalog no. ab104513; Abcam, Cambridge, UK), and GAPDH (catalog no. MAB374; EMD Millipore, Billerica, Mass). After incubation with the appropriate horseradish peroxidase-associated secondary antibodies (Santa Cruz Biotechnology, Santa Cruz, Calif), bands were visualized with an enhanced chemiluminescence detection system (Thermo Fisher Scientific, Waltham, Mass) and imaged on a ChemiDoc Touch Imaging System using Image Lab v5.2.1 Build 11 software (Bio-Rad). Protein levels were semiquantified by densitometry.

\section{TF Procoagulant Activity}

TF procoagulant activity was analyzed using the Abcam Tissue Factor Activity Kit (catalog no. ab108906) in accordance with the manufacturer's instructions. In brief, HUVECs were lysed in RIPA buffer, and $50 \mu \mathrm{g}$ of protein from each sample was used for measuring TF activity. Samples were incubated with extrinsic tenase complex (containing factors VII and
$\mathrm{X}$ ) and $\mathrm{CaCl}_{2}$. The reaction was terminated by the addition of EDTA buffer. Finally, a chromogenic substrate (Spectrozyme FXa) was added, and absorbance was measured at $405 \mathrm{~nm}$ on a SPECTRAmax plate reader (Molecular Devices, Sunnyvale, Calif) every 2 minutes for 16 minutes. All samples and controls were performed in triplicate.

\section{Generation of EC-Specific ATG7 Knockout Mice}

Floxed $A T G 7$ mice (ATG $7^{f l o x}$ flox mice) were crossed with VE-cadherin Cre transgenic mice to generate EC-specific $A T G 7$ knockout $\left(\mathrm{EC}_{-} \mathrm{ATG} 7^{-1-}\right)$ mice. The characterization of these mice has been described previously. ${ }^{29,36}$ Wild-type littermate (WT) mice were used as the control group. All animal-related procedures were reviewed and approved by the St. Michael's Hospital Animal Care Committee. All experiments and data collection were conducted in a blinded fashion to eliminate any potential observer bias.

\section{Detection of $\beta 3$ Integrin and P-Selectin on the Platelet Surface}

To examine whether loss of endothelial ATG7 affects platelet activation or granule release, we incubated resting and activated ( $1 \mathrm{U} / \mathrm{mL}$ thrombin) gel-filtered platelets $\left(10^{6}\right)$ from WT and EC-ATG7 ${ }^{-1-}$ mice for 30 min with rat anti-mouse phycoerythrin-conjugated $\alpha \operatorname{Ilb} \beta 3$ antibodies (JON/A, $10 \mu \mathrm{g} / \mathrm{mL}$; Emfret Analytics, Eibelstadt, Germany) or fluorescein isothiocyanate-conjugated rat anti-mouse CD62P (P-selectin, $10 \mu \mathrm{g} / \mathrm{mL}$; BD Biosciences, San Jose, Calif) monoclonal antibodies. Platelets were fixed with freshly prepared paraformaldehyde $(1 \%)$ and antibodies detected by a FACScan flow cytometer (BD Biosciences).

\section{$\mathrm{FeCl}_{3}$-Induced Carotid Artery Thrombosis Model}

The $\mathrm{FeCl}_{3}$-induced carotid artery thrombosis model was performed as described previously ( $\mathrm{n}=9$ per group) ${ }^{37,38}$ In brief, WT and EC-ATG7 ${ }^{-1-}$ mice were anesthetized with tribromoethanol (Avertin $2.5 \%, 0.015 \mathrm{~mL} / \mathrm{g}$ body weight) delivered intraperitoneally. The left common carotid artery was isolated, and injury was induced by applying a $1 \times 1$-mm filter paper presoaked in $5 \% \mathrm{FeCl}_{3}$ to the external surface for $3 \mathrm{~min}$. Clot formation was assessed by monitoring blood flow with a flow meter and a $0.5-\mathrm{mm}$ flow probe (0.5PSB Precision S-Series; Transonic Systems, Ithaca, NY) before $\mathrm{FeCl}_{3}$ application and for 60 minutes thereafter. The experiment was terminated when blood flow decreased to $<20 \%$ of the baseline value for at least 3 minutes or up to 60 minutes thereafter.

\section{$\mathrm{FeCl}_{3}$-Induced Mesenteric Arterial Thrombosis Model}

The $\mathrm{FeCl}_{3}$-induced mesenteric arterial thrombosis model was performed as described previously in $11 \mathrm{WT}$ mice and $10 \mathrm{EC}-\mathrm{ATG} 7^{-1-}$ mice. ${ }^{37,38} \mathrm{In}$ brief, WT and EC-ATG7 ${ }^{-1-}$ mice were anesthetized with tribromoethanol (Avertin $2.5 \%, 0.015 \mathrm{~mL} / \mathrm{g}$ body weight) delivered intraperitoneally. Gelfiltered platelets were fluorescently labeled with calcein acetoxymethyl ester $(1 \mu \mathrm{g} / \mathrm{mL}$; Molecular Probes) and injected via the tail vein of recipient mice (age 23-28 days). The mesentery vascular bed was exteriorized through a midline abdominal incision. A single arteriole was chosen in each mouse based on vessel diameter $(80-120 \mu \mathrm{m})$, shear rate (approximately $1500 \mathrm{~s}^{-1}$ ), and visibility. Thrombus formation was induced in a 2- to 5$\mathrm{mm}$ segment of the arteriole by topical application of $30 \mu \mathrm{L}$ of $250 \mathrm{mM}$ $\mathrm{FeCl}_{3}$. After initiation of $\mathrm{FeCl}_{3}$ injury, the vessel occlusion time was defined as complete cessation of blood flow for at least 2 minutes.

\section{Laser-Induced Cremasteric Arteriolar Thrombosis Model}

We also studied thrombus formation in WT and EC-ATG $7^{-1-}$ mice using a laser-induced cremasteric arteriolar thrombosis model, as described previously ( $\mathrm{n}=3$ per group). ${ }^{37-39}$ In brief, WT and EC-ATG $7^{-1-}$ mice 
were anesthetized with tribromoethanol (Avertin $2.5 \% ; 0.015 \mathrm{~mL} / \mathrm{g}$ body weight) delivered intraperitoneally. The cremaster muscles of anesthetized mice were exposed under a dissecting microscope and superfused with preheated bicarbonate-buffered saline throughout the experiment. Platelets were labeled with a Dylight647 Mouse Platelet Labeling Reagent (Emfret Analytics, Eibelstadt, Germany) and delivered via a jugular vein cannulus. Multiple independent injuries were then caused by a pulsed nitrogen dye laser. A total of 36 thrombi in 3 WT mice (12 per mouse) and 34 thrombi in 3 EC-ATG7 ${ }^{-1-}$ mice were studied. Real-time images of thrombus formation in response to vascular injury were captured using an Olympus BX51WI fluorescent microscope (Olympus, Richmond Hill, Ontario, Canada) and quantified using Slidebook software (Intelligent Imaging Solutions, Denver, Colo).

\section{Tail Bleeding Model}

To assess bleeding time, WT and EC-ATG7 $7^{-1-}$ mice were anesthetized with tribromoethanol (Avertin $2.5 \%, 0.015 \mathrm{~mL} / \mathrm{g}$ of body weight, intraperitoneal) and placed on a $37^{\circ} \mathrm{C}$ warming pad ( $\mathrm{n}=8$ /group). Using a sharp scalpel, a cut was made to remove $3 \mathrm{~mm}$ of the distal tail. The tail was immersed in phosphate-buffered saline at $37^{\circ} \mathrm{C}$ and measured for bleeding. Time to bleeding cessation was recorded when bleeding stopped for at least 30 seconds or up to 60 minutes thereafter.

\section{Statistical Analysis}

Data are expressed as mean \pm standard error of the mean unless indicated otherwise. Student's $t$ test was applied when the means of two groups were compared. Differences among multiple means were evaluated by ANOVA and then followed by post-hoc analysis with the Bonferroni's test. A $P$ value $<.05$ was considered to indicate statistical significance.

\section{RESULTS}

\section{Loss of ATG7 Attenuates TF Expression in HUVECs}

To determine the effect of ATG7 knockdown on TF expression, HUVECs were incubated with siATG7 or nonspecific, scrambled siRNA (scrambled control) as a control. Outcome measurements with nontransfected HUVECs were similar to those from scrambled control (data not shown) and were not used for comparisons. As shown in Figure 1, A, ATG7 mRNA levels were decreased by $64 \%$ after 24 hours of treatment with siATG7. Similarly, protein levels of ATG7 were decreased after 72 hours of treatment with siATG7 (Figure 1,B). TNF- $\alpha$ had no significant effect on ATG7 mRNA or protein levels after siATG7 treatment.

In the absence of TNF- $\alpha$, TF mRNA levels in HUVECs treated with siATG7 were similar to those in HUVECs treated with the scrambled control. HUVECs treated with TNF- $\alpha$ and scrambled control had significantly higher TF mRNA levels $(16$-fold; $P<.001)$ compared with those that had not been exposed to TNF- $\alpha$ (Figure 1, $C$ ). TF mRNA expression in HUVECs exposed to both TNF- $\alpha$ and siATG7 was significantly lower (a reduction of $63 \% ; P=.02$ ) than that in HUVECs treated with TNF- $\alpha$ and the scrambled control (Figure 1,C). In the presence of TNF- $\alpha$, this inhibitory effect was time-dependent, as evidenced by the significant temporal change in TF mRNA expression $(P<.05)$, with a $51 \%$ decrease after 48 hours and a $67 \%$ decrease after 72 hours of siRNA treatment, with no difference after 24 hours (Figure 1, D). TNF- $\alpha$-induced TF protein expression was examined at 72 hours post-transfection, and siATG7 treatment was found to significantly reduce TF content by $58 \%(P=.05)$ compared with the effects of the scrambled control (Figure 1, E). Similarly, TNF- $\alpha-$ induced TF activity levels were significantly reduced, by $65 \%(P=.02)$, in siATG7-treated HUVECs compared with scrambled control after 72 hours (Figure 1,F). Taken together, these results demonstrate that the loss of endothelial ATG7 attenuates TNF- $\alpha$-induced expression of TF, suggesting that endothelial ATG7 plays a role in the regulation of TF expression in HUVECs.

\section{Loss of Endothelial ATG7 Has No Effect on Platelet Function in Mice}

To evaluate the potential translational implications of our in vitro results and to circumvent the early lethality observed previously in systemic ATG7 knockout mice, ${ }^{21}$ we generated EC-ATG7 ${ }^{-1-}$ mice, conditional knockout mice in which ATG7 was deleted only in ECs. ${ }^{36}$ EC-ATG7 ${ }^{-1-}$ mice were born in a Mendelian ratio and did not present with any apparent basal phenotype. To exclude intrinsic changes in platelets after endothelial $A T G 7$ knockout, we evaluated platelet surface expression of CD61 and CD62, prominent receptors for platelet adhesion and aggregation, in vitro. As shown in Figure 2, the platelet surface expression levels of $\beta 3$ integrin (CD61; Figure 2, A) and P-selectin (CD62; Figure $2, B$ ) were similar in resting and thrombin (1 $\mathrm{U} / \mathrm{mL}$ )-activated platelets. No difference was found between platelets from control and EC-ATG7 $7^{-1-}$ mice. We enumerated platelets and observed no significant difference in blood platelet counts between WT and EC-ATG $7^{-1-}$ mice (Figure 2, C). Therefore, loss of endothelial ATG7 has no effect on platelet counts or function.

\section{Loss of Endothelial ATG7 Attenuates $\mathrm{FeCl}_{3}$-Induced Carotid Artery TF Expression and Thrombosis}

To further validate our in vitro observations, we analyzed TF expression in the carotid arteries of WT and EC-ATG $7^{-1-}$ mice that had been subjected to $\mathrm{FeCl}_{3}$-induced endothelial injury. Basal carotid levels of TF mRNA were indistinguishable between the 2 genotypes. In WT carotid arteries, $\mathrm{FeCl}_{3}$ stimulation was associated with a significant $(P=.05) 2$-fold increase in TF mRNA levels (Figure 3, $A$ ) relative to that in uninjured carotid arteries from WT mice. Notably, TF mRNA levels in $\mathrm{FeCl}_{3}$-injured carotid arteries of EC$\mathrm{ATG}^{-1-}$ mice were not statistically different from those in uninjured samples from WT and EC-ATG $7^{-1-}$ mice. This observation coincides with the lower TF expression recorded in ATG7-silenced HUVECs, supporting the contention that ATG7 is a regulator of TF transcription in injured or inflamed endothelium.

Endothelial loss of $A T G 7$ attenuated thrombus formation in EC-ATG7 ${ }^{-1-}$ mice after $\mathrm{FeCl}_{3}$-induced vascular injury. As shown in Figure 3, $B$, the time to carotid artery occlusion was 

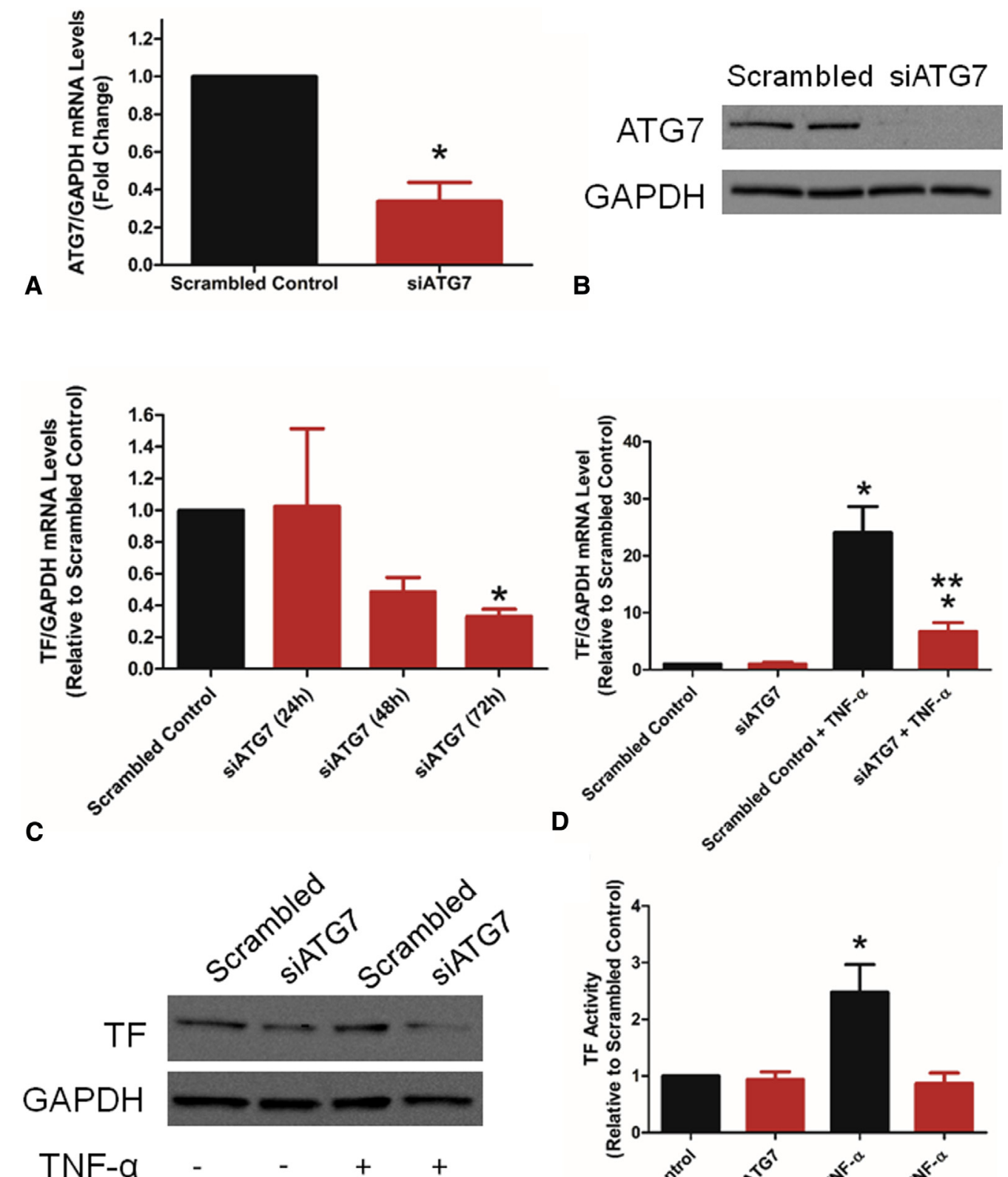

\section{E}

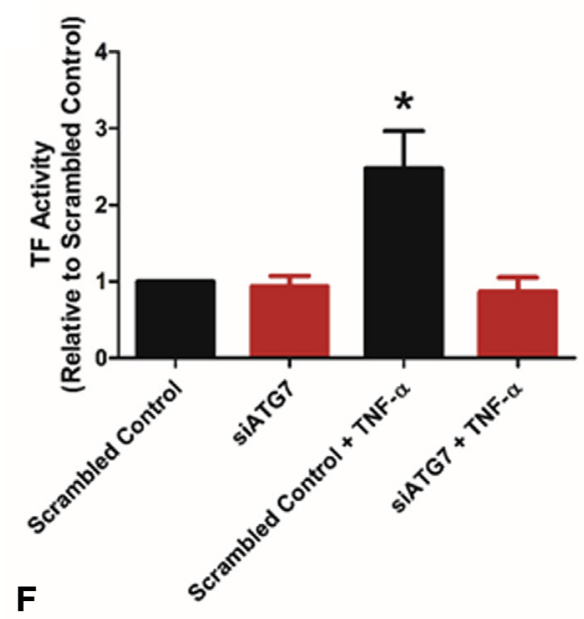

FIGURE 1. Loss of ATG7 attenuates TNF- $\alpha$-induced expression of TF in HUVECs. HUVECs were transfected with scrambled control or siATG7 (5 nM) for 72 hours. Before harvesting, HUVECs were incubated for 4 hours in the presence or absence of $20 \mathrm{ng} / \mathrm{mL}$ TNF- $\alpha$. A, mRNA analysis of ATG7 was performed by qRT-PCR. The data are presented as fold change to that obtained with the scrambled control. qRT-PCR revealed successful silencing of ATG7 after 24 hours. B, Western blot analysis of ATG7 was performed and compared with GAPDH as a loading control. Western blot revealed successful silencing of ATG7 after 72 hours. In both situations, TNF- $\alpha$ had no effect on ATG7 mRNA or protein expression. C, qRT-PCR was conducted on total RNA extracted 72 hours after silencing was initiated. TNF- $\alpha$ induced the expression of TF mRNA in HUVECs. D, Quantitative analysis indicated that siATG7 transfection significantly and time-dependently reduced TF mRNA expression in HUVECs. Differential transcript data, presented as fold change to the scrambled control, indicate that ATG7 knockdown attenuated TF transcript in a time-dependent fashion. E, HUVECs were incubated with $20 \mathrm{ng} / \mathrm{mL}$ TNF- $\alpha$, and protein was extracted at the 72-hour time point for Western blot analysis. F, TF activity of HUVECs with or without TNF- $\alpha$ administration for 4 hours. FXa activity was quantified at $405 \mathrm{~nm}$ after the addition of FXa substrate. The procoagulant activity of TF was expressed as change relative to the activity of HUVECs treated with scrambled control. $* P<.05$, $* * * P<.0001$ versus corresponding scrambled control group. All experiments were performed independently 3 to 5 times, and each experimental set was conducted in triplicate. ATG7, Autophagy-related 7; GAPGH, glyceraldehyde 3-phosphate dehydrogenase; SiATG7, small interfering autophagy-related 7; $T F$, tissue factor; $T N F$, tumor necrosis factor. 


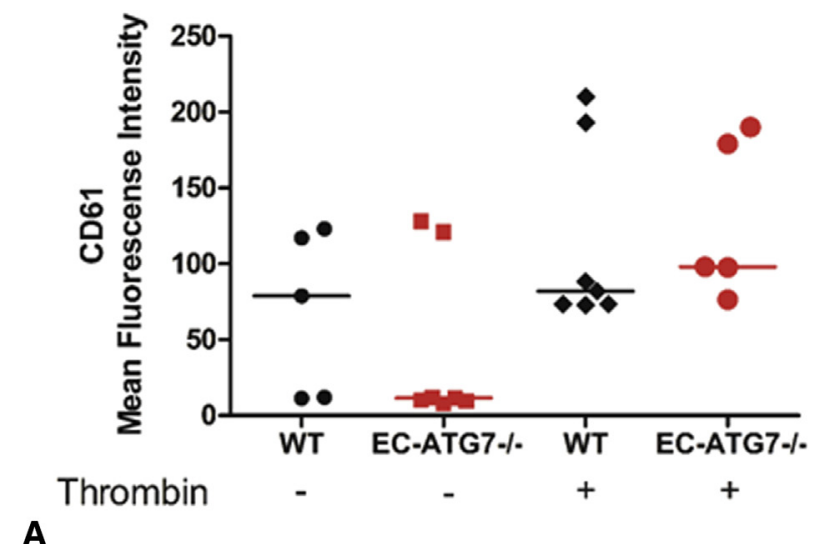

A

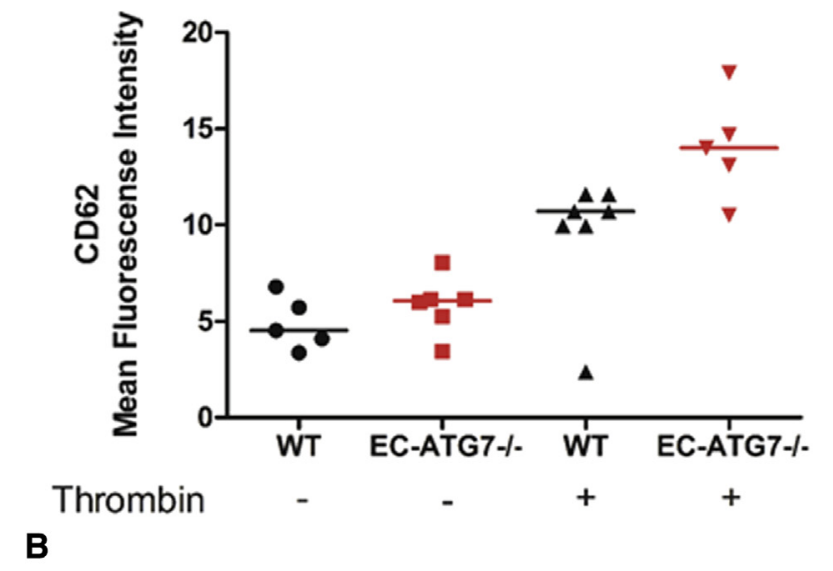

C

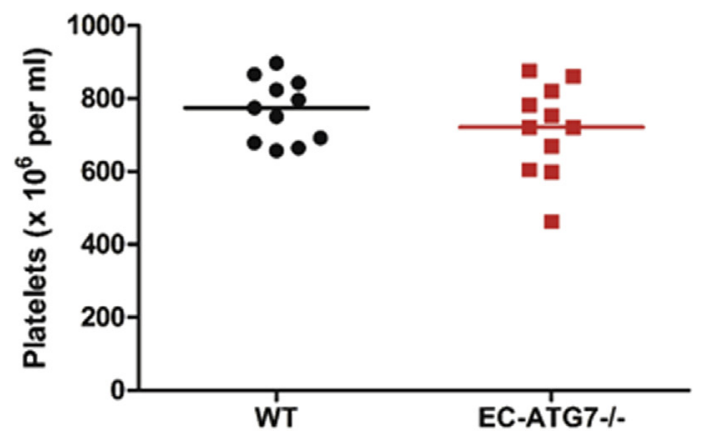

FIGURE 2. WT and EC-ATG $7^{-1-}$ mice have similar platelet function and plasma platelet counts. Surface expression of $\beta 3$ integrin (CD61) (A) and P-selectin (CD62) (B) on resting and thrombin (1 U/mL)-stimulated platelets from WT (black) and EC-ATG7 ${ }^{-1-}$ (red) mice were analyzed by flow cytometry. C, Platelet counts were determined in plasma from WT (black) and EC-ATG7 $7^{-1-}$ (white) mice. No significant difference was observed. Each point represents a separate mouse; lines represent median values. $\mathrm{n}=10 /$ group for all 3 parameters. WT, Wild type; $E C$, endothelial cell; ATG7, autophagy-related 7.

significantly $(P=.003)$ prolonged by 2 -fold in EC-ATG7 ${ }^{-1-}$ mice compared with WT mice $(31.0 \pm 12$ minutes vs $15.5 \pm 6.0$ minutes). Taken together, these results show that
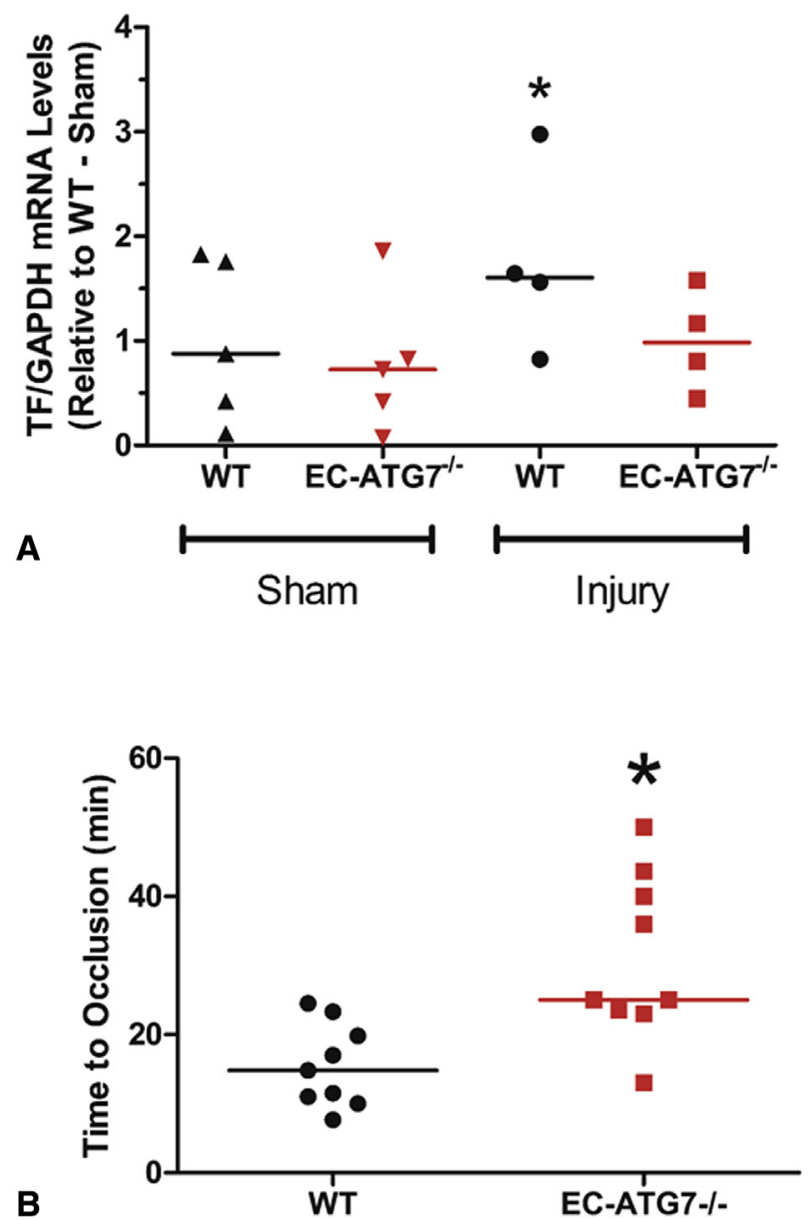

FIGURE 3. Loss of ATG7 is associated with dysfunctional thrombosis and reduced TF mRNA expression after $\mathrm{FeCl}_{3}$-induced carotid artery injury. Thrombosis was initiated by application of a $1 \times 1$-mm filter paper presoaked in $5 \% \mathrm{FeCl}_{3}$ for 3 minutes to the left carotid artery. Blood flow was measured continuously for up to 60 minutes. Time to occlusion was defined as the time required for blood flow to cease for at least 3 minutes. A, Quantitative analysis of TF mRNA expression in the carotid arteries of WT (black) and EC-ATG7 ${ }^{-1-}$ (red) mice. Total RNA was extracted from the carotid artery after occlusion. Differential transcript (qRT-PCR) data are presented as fold change to WT without $\mathrm{FeCl}_{3}$ injury. B, Time to vessel occlusion was prolonged in EC-ATG7 $7^{-1-}$ mice compared with WT mice. Each point represents a separate mouse. Lines show median values. $* P<.05$ versus WT. TF, Tissue factor; GAPGH, glyceraldehyde 3-phosphate dehydrogenase; $W T$, wild type; $E C$, endothelial cell; $A T G 7$, autophagy-related 7 .

TF expression is mediated by $A T G 7$, an observation that is in alignment with the previously described in vitro data, and that loss of endothelial ATG7 results in an antithrombotic phenotype, suggesting that endothelial ATG7 modulates thrombus formation in a TF-dependent manner.

\section{Loss of Endothelial ATG7 Attenuates $\mathrm{FeCl}_{3}$-Induced Mesenteric Arterial Thrombosis}

We next examined whether the antithrombotic activity associated with ATG7 knockdown also occurs in the 

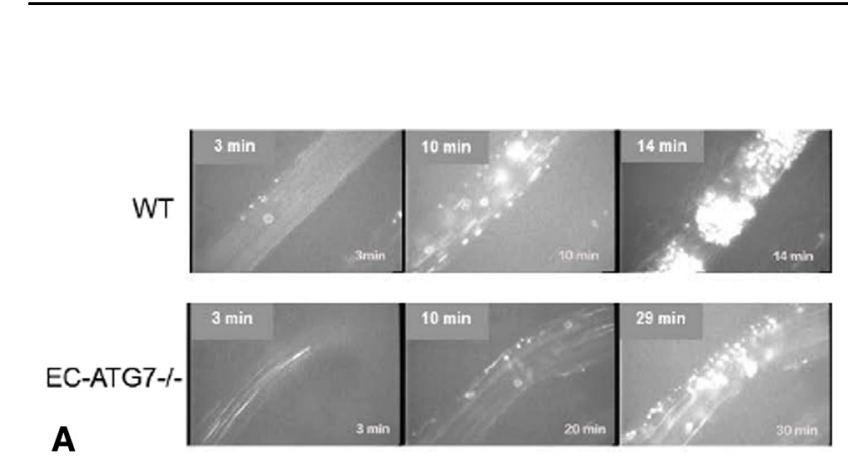

A

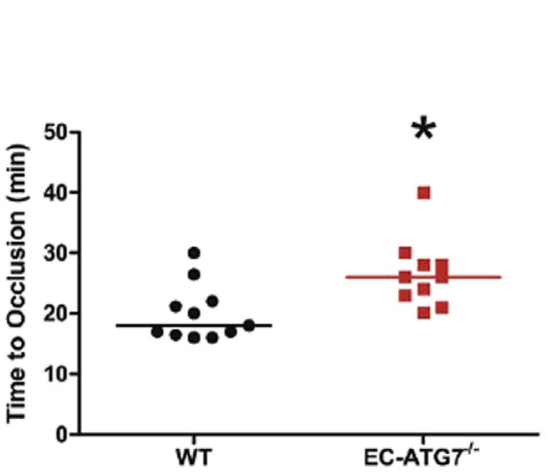

FIGURE 4. Loss of ATG7 is associated with dysfunctional thrombosis after $\mathrm{FeCl}_{3}$-induced mesenteric arterial injury. Mice were given an intravenous injection of fluorescent-labeled platelets before injury. Thrombosis was initiated by application of $5 \% \mathrm{FeCl}_{3}$ directly to the mesenteric artery. Blood flow was measured continuously up to 60 minutes after injury. A, Thrombus growth and vessel occlusion were attenuated in EC-ATG7 ${ }^{-1-}$ mice. B, Quantitative analysis of thrombus formation in WT (black) and ${\mathrm{EC}-\mathrm{ATG}^{-1}}^{-}$(red) mice. Time to occlusion was defined as the time required for blood to cease for at least 3 minutes. Each point represents a separate mouse; lines represent median values. ${ }^{*} P<.05$ versus WT. WT, Wild type; $E C$, endothelial cell; $A T G 7$, autophagy-related 7.

mesenteric arteriolar network. As shown in Figure 4, A, $\mathrm{FeCl}_{3}$-triggered platelet deposition in the mesenteric vasculature of WT mice occurred at an earlier time point relative to that in EC-ATG7 $7^{-1-}$ mice, supporting the existence of an $A T G 7$-thrombosis regulatory axis. Given that the time to mesenteric arteriole occlusion was significantly $(P=.008)$ prolonged by 1.3 -fold in EC-ATG7 ${ }^{-1-}$ mice compared with WT mice (26.6 \pm 5.7 and $20.0 \pm 4.6$ minutes, respectively; Figure 4, B), our collective results provide additional confirmation that $\mathrm{FeCl}_{3}$ induced thrombosis is modulated by endothelial ATG7.

\section{Loss of Endothelial ATG7 Attenuates Laser-Induced Cremasteric Arteriolar Thrombosis}

To quantify thrombi development, we used a laserinduced cremasteric arteriolar thrombosis model to determine the platelet accumulation within a growing thrombus in WT and EC-ATG7 $7^{-1-}$ mice. In WT mice, platelets adhered and quickly accumulated at the site of injury immediately after laser-induced arterial injury (Figure 5, $A$ ). The thrombus rapidly increased in size, reaching its maximum size approximately 1 minute after injury. In EC-ATG7 $7^{-/-}$
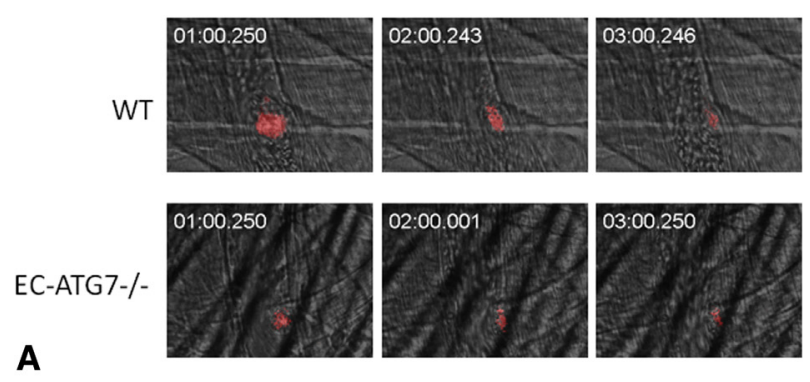

B
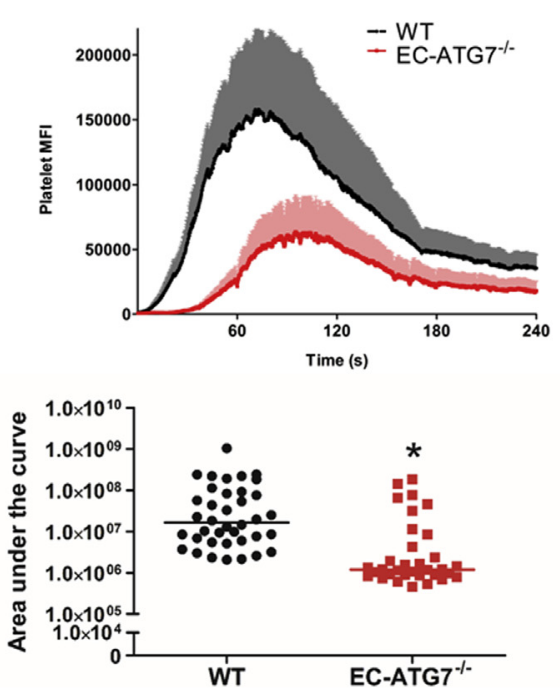

C

FIGURE 5. Thrombus formation in $\mathrm{WT}$ and $\mathrm{EC}-\mathrm{ATG} 7^{-1-}$ mice using the laser-induced cremasteric arteriolar injury. A, Representative images of thrombus formation at 1,2, and 3 minutes after arterial injuries for each group (red, platelets). B, The kinetic curves represent platelet mean fluorescence intensity (MFI) of thrombus formation, and the shaded regions represent SEM. C, Area under the curve also was compared for each group between WT $\left(\mathrm{n}=36\right.$ thrombi) and EC-ATG $7^{-1-}$ mice. Each point represents a separate mouse; lines represent median values. $\mathrm{N}=34$ thrombi. ${ }^{*} P<.05$ versus WT. WT, Wild type; $E C$, endothelial cell; ATG7, autophagy-related 7.

mice, platelet thrombus formation at the site of injury was significantly smaller and delayed compared with WT mice. The thrombi seen in the EC-ATG $7^{-1-}$ mice appeared fragile and unstable; frequent embolization and detachment of whole thrombi was evident. In sharp contrast, thrombi in WT mice exhibited rapid platelet accumulation within the growing thrombus. Compared with WT mice, EC-ATG7 ${ }^{-l-}$ mice had significantly $(P<.001)$ fewer platelets within the thrombi and a lower rate of platelet deposition (Figure 5, B). These findings in the cremasteric arterioles confirmed our initial observations that ATG7 contributes to thrombus formation.

\section{Loss of Endothelial ATG7 Exacerbates Tail Bleeding}

To verify whether ATG7 affects hemostasis, tail bleeding times were compared between $\mathrm{WT}$ and EC-ATG $7^{-1-}$ mice. 


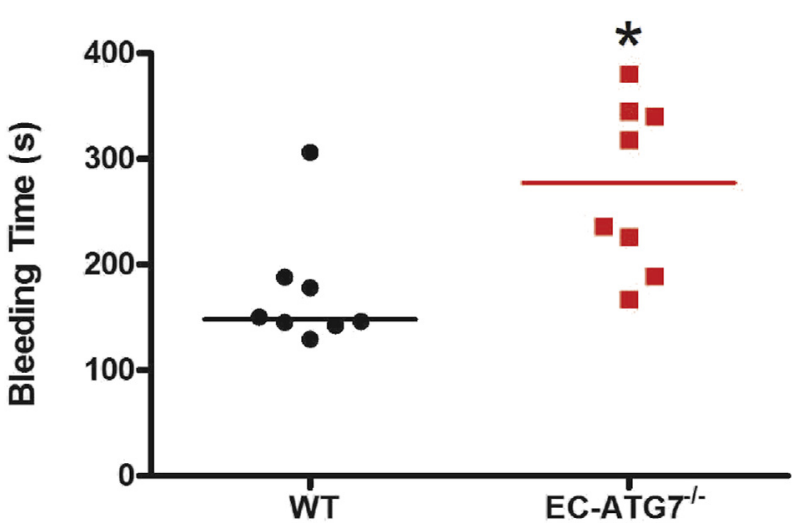

FIGURE 6. Loss of ATG7 is associated with prolonged bleeding times. Time to bleeding cessation was measured for 60-min after tail-tip amputation in WT and $\mathrm{EC}-\mathrm{ATG} 7^{-\prime-}$ mice ( $\mathrm{n}=8$ per group). Each point represents a separate mouse; lines represent median values. ${ }^{*} P<.05$ versus WT. WT, Wild type; $E C$, endothelial cell; $A T G 7$, autophagy-related 7.

Tail bleeding times after tail transection were significantly $(P<.05)$ longer in the EC-ATG7 ${ }^{-1-}$ mice $(275 \pm 80$ and $173 \pm 57$ seconds, respectively) (Figure 6).

\section{DISCUSSION}

There is increasing interest in the role of autophagic flux in maintaining normal vessel wall homeostasis and growing support for the idea that autophagic dysregulation may be a common pathway through which vascular aging and associated pathologies develop. ${ }^{5,29,40}$ Within ECs and smooth muscle cells, diverse but important triggers, such as oxidized lipids to $\beta$-amyloid, seem to stimulate autophagosome formation potently, and emerging evidence link autophagy to a wide array of vascular processes, ranging from angiogenesis to calcification of the vessel wall. ${ }^{5}$ Alterations in autophagic flux also are increasingly being implicated in disease processes that include both atherosclerosis and pulmonary hypertension and there are reports suggesting that autophagy also may modulate the paracrine regulation of vasoactive substances from the endothelium. Torisu and colleagues ${ }^{36}$ recently demonstrated that endothelial autophagy plays a critical role in the bioactivity of von Willebrand factor. Although in vivo thrombosis was not evaluated in these studies, the data suggest that an intact autophagic machinery may be responsible for the cellular processing and secretion of endothelial factors important in paracrine and autocrine regulation of thrombosis.

In the present study, we have made the important translational observation indicating an essential role of endothelial autophagy in the regulation of thrombosis in vivo (Video 1). Specifically, we suggest that loss of endothelial ATG7, an essential autophagy component, attenuates TNF- $\alpha$-induced expression of TF in HUVECs and reduces the level of TF mRNA in mice after $\mathrm{FeCl}_{3}$ injury, a model of endothelial

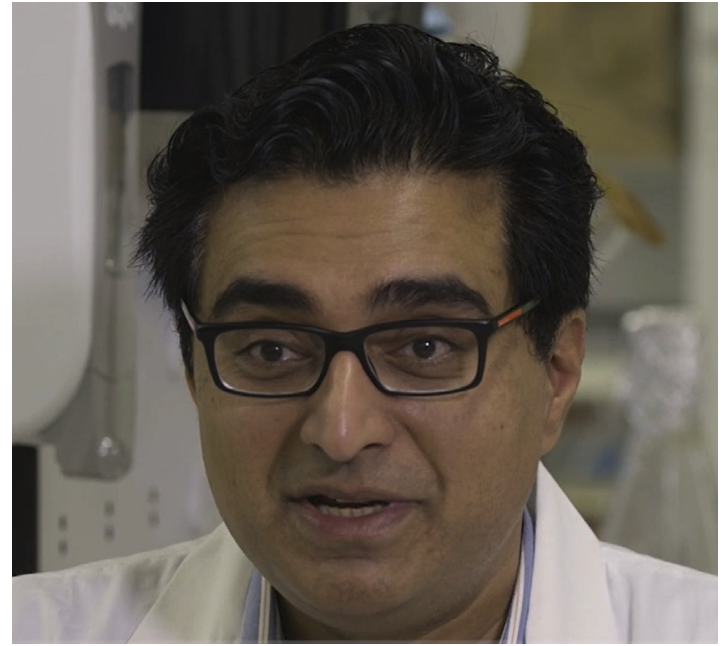

VIDEO 1. Interview with the authors about the translational implications of the study findings. Video available at: http://www.jtcvsonline.org/ article/S0022-5223(17)30420-8/addons.

injury. Importantly, the results from the 3 in vivo models of thrombosis described herein clearly demonstrate that EC-ATG7 ${ }^{-1-}$ mice exhibit dysfunctional thrombus formation. Consequently, we postulate that intact endothelial ATG7 is essential in regulating thrombosis, in part through a TF-dependent mechanism.

There are limited studies evaluating the role of autophagy on thrombosis susceptibility and there remains conflicting hypotheses regarding whether it plays an antithrombotic or prothrombotic role. For example, megakaryocyte- and platelet-specific knockout of $A T G 7$ mice is associated with a modest decrease in platelet aggregation and a prolonged time to vessel occlusion and cessation of bleeding in a tail bleeding model,${ }^{36}$ suggesting that loss of platelet autophagy confers an antithrombotic phenotype. The present study extends the observations made in platelets to ECs. First, prolonged vessel occlusion times were observed in the carotid arteries and mesenteric arterioles of EC$\mathrm{ATG}^{-1-}$ mice on $\mathrm{FeCl}_{3}$ injury. Second, initial platelet deposition, which is required for thrombus growth, was attenuated in EC-ATG7 ${ }^{-1-}$ mice. Finally, thrombus formation was retarded in the cremasteric arterioles of EC-ATG $7^{-1-}$ mice on laser-induced injury. Therefore, loss of endothelial ATG7 is sufficient to affect the susceptibility of thrombosis in vivo, and the magnitude of these differences is quite large, and highly statistically significant.

$\mathrm{TF}$, a primary initiator of the extrinsic blood coagulation pathway, resides in the necrotic core of atherosclerotic plaques and triggers thrombosis on plaque rupture. ${ }^{41}$ On contact with activated factor VIIa, TF activates the blood coagulation cascade, which sets into motion sequential enzymatic reactions that eventually culminate in the production of thrombin, the key enzyme for fibrin formation and platelet activation. Despite our intimate understanding 
of the coagulation components, ${ }^{42}$ their triggers and partnerships, specific details as to how ECs regulate TF expression and thus initiate thrombosis have not been completely elucidated. Two lines of evidence further support the concept that endothelial ATG7 modulates coagulation via TF transcription. First, loss of ATG7 attenuates TNF- $\alpha$-induced TF mRNA and expression in HUVECs in a timedependent manner. Second, EC-specific deletion of ATG7 is linked to reduced TF mRNA expression in murine carotid arteries after $\mathrm{FeCl}_{3}$ injury, a model driven, at least in part, by thrombin. ${ }^{43}$ Our results suggest that ATG7 regulates TF expression through control of TF gene transcription, as shown by reduced TF mRNA expression in both cultured ECs and mice. There have been reports alluding to a role for autophagy in TF expression and release. ${ }^{44,45}$ In human hepatocellular carcinoma tissues, the levels of autophagic markers and TF expression are inversely correlated, and coagulation factors such as TF repress autophagy via mechanistic target of rapamycin through an ATG7dependent pathway. ${ }^{44}$ It also has been reported that TFs are localized to neutrophil extracellular traps, and that a proinflammatory environment such as that induced by TNF- $\alpha$ (potentially during/after cardiopulmonary bypass/ artificial blood surface interface and percutaneous transluminal coronary angioplasty balloon inflation) can trigger NET-mediated TF release in an autophagy-dependent manner. ${ }^{45}$ Accordingly, we propose that in ATG7-silenced HUVECs, the loss of ATG7-associated autophagy dampens TNF- $\alpha$-triggered TF transcription and translation, which in turn leads to a reduction in TF release (Figure 7). Likewise, the silencing of ATG7 in EC-ATG7 ${ }^{-1-}$ mice tempers the TF synthesis pathways, resulting in an antithrombotic phenotype (Figure 7).

We have previously found that loss of endothelial ATG7, both in vitro and in vivo, is associated with endothelial-tomesenchymal transition-like phenotypic switching. ${ }^{29}$ Therefore, it is possible that reduced $\mathrm{TF}$ expression is due to a phenotypic alteration in endothelial biology/structure/function. Furthermore, TF expression and activity can be induced in vascular smooth muscle cells, ECs, and monocytes by

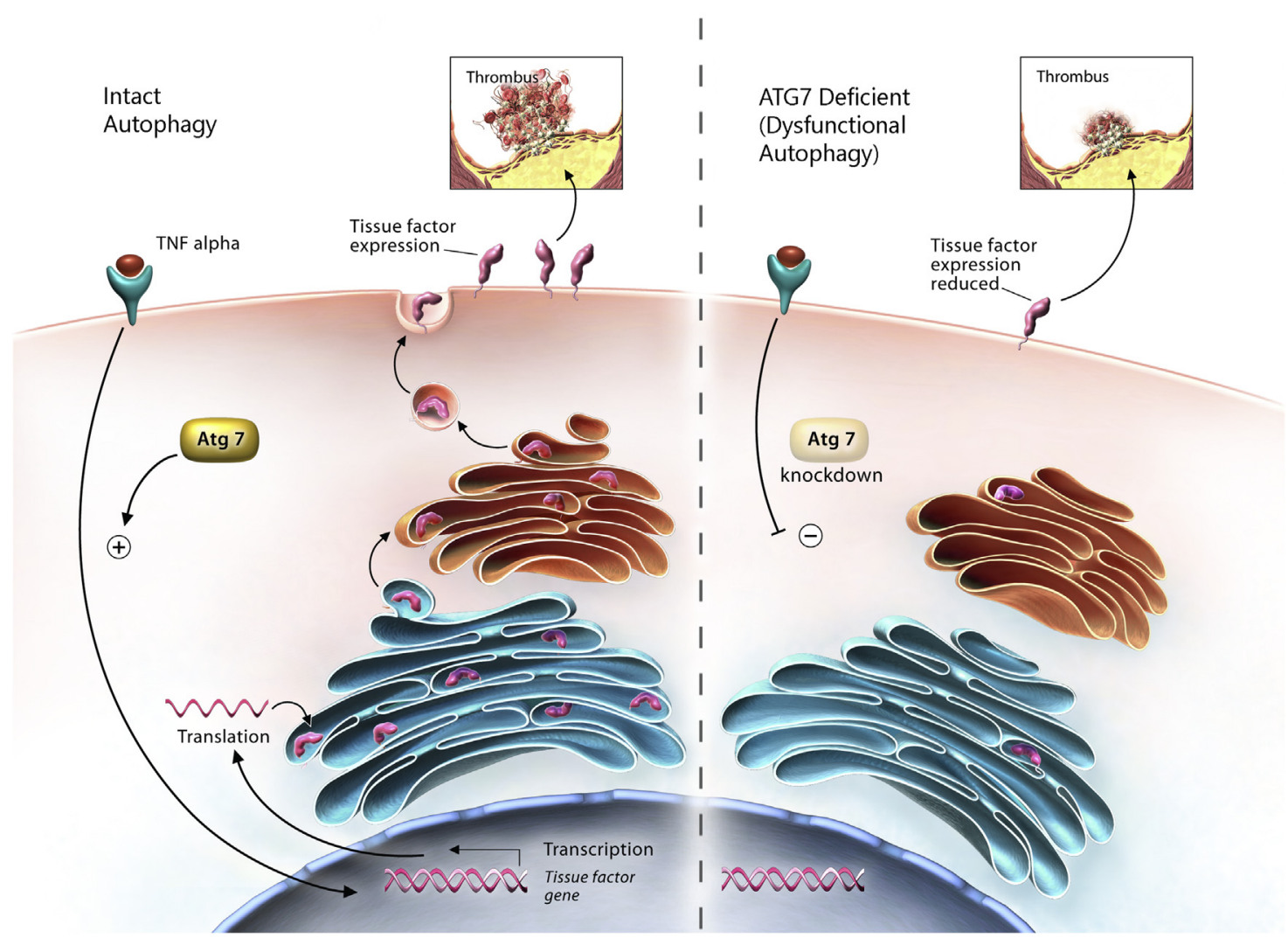

FIGURE 7. A schematic representation of the role of ATG7 in the regulation of TF expression and thrombus formation in ECs. In the presence of an intact endothelial autophagy system (left), vascular injury and inflammatory stimuli such as TNF- $\alpha$ independently promote the transcription of TF in ECs. Consequently, TF translation at the level of the endoplasmic reticulum (blue stacks) is enhanced and the newly synthesized TF proteins are transported via the endoplasmic reticulum-Golgi complex (red stacks) to the cell surface, where they proceed to initiate the thrombosis cascade. In the absence of ATG7 and, accordingly, a loss of critical autophagy machinery (right), TF transcription, translation, and translocation in response to the usual thrombosis triggers are significantly dampened. The downstream impact of TF is decreased accordingly, culminating in an appreciably more antithrombotic (vs prothrombotic) presentation. WT, Wild type; $E C$, endothelial cell; $A T G 7$, autophagy-related 7. 
various stimuli, including proinflammatory cytokines, such as TNF- $\alpha$, and vascular injury by either ligation, photoreactive dyes, $\mathrm{FeCl}_{3}$, or laser. ${ }^{43}$ Notably, these in turn induce various transcriptional mechanisms involving cooperation of transcriptional factors from Jun/Fos, NF-kB, NFAT, Egr, and SP-1 families. ${ }^{46}$ Clearly, more studies that dissect the role of ATG7 in TF mRNA expression, and endothelial TF processing would be informative; however, these studies are beyond the scope of this paper.

The clinical implications of this research are that loss of autophagic flux may decrease the risk of thrombosis, and that regulation of the autophagy pathway may modulate the prothrombotic response. Currently, there is a lack of clear clinical evidence demonstrating whether the modulation of autophagy can affect the development of thrombosis. However, in patients undergoing percutaneous coronary intervention with stenting, in-stent thrombosis was associated with stents coated with rapamycin, ${ }^{47}$ a potent activator of autophagy. ${ }^{48}$ Preclinical studies also have shown that mice given rapamycin demonstrated an increase in thrombosis. ${ }^{49}$ Furthermore, treatment with rapamycin in cultured human aortic ECs or mice has been associated with an increase in endothelial TF expression. ${ }^{49,50}$ The present study uses several experimental models of thrombosis in animals and offers plausible evidence that ATG7 is an essential gene for autophagy, ${ }^{22}$ although an alternate ATG7-independent route exists to allow for autophagy to occur even in the absence of ATG7. ${ }^{51}$ Autophagosome formation and protein degradation occur in the ATG7-independent process of autophagy, but lipidation of LC3 to form LC3-II does not follow suit. ${ }^{51}$ In the present study, we were unable to exclude a role for ATG7-independent mechanisms of autophagy The possibility of other downstream effects of ATG7 loss other than autophagy is also a possible mechanism for the observed reduced thrombosis phenotype in our model and warrants further investigation to evaluate thrombosis following pharmacologic inhibition or genetic deletion of another essential gene for autophagy (eg, $\mathrm{ATG} 5^{52}$ ) to delineate the precise role of autophagy in thrombosis.

In conclusion, the present study demonstrates an essential role of endothelial ATG7 as a regulator of thrombosis susceptibility in vivo. Furthermore, we have shown that ATG7 may mediate this response through endothelial regulation of TF on endothelial activation (Figure 7). We have provided evidence for the importance of ECs in thrombosis and a body of data that support endothelial ATG7 as a potential target to reduce thrombosis. Specifically, our results speak to the therapeutic potential of either enhancing ATG7 expression or minimizing ATG7 loss to limit thrombosis (Video 1).

\section{Conflict of Interest Statement}

Authors have nothing to disclose with regard to commercial support.
We thank Dr Toren Finkel, National Institutes of Health, for his insights and helpful comments and suggestions.

\section{References}

1. Raskob GE, Angchaisuksiri P, Blanco AN, Buller H, Gallus A, Hunt BJ, et al. Thrombosis: a major contributor to global disease burden. Arterioscler Thromb Vasc Biol. 2014:34:2363-71.

2. Raja S, Blackstone EH, Murthy SC. Caught between a rock and a hard place: venous thromboembolism screening in high-risk patients. $J$ Thorac Cardiovasc Surg. 2016;151:1000-1.

3. White E. The role for autophagy in cancer. J Clin Invest. 2015;125:42-6.

4. Gatica D, Chiong M, Lavandero S, Klionsky DJ. Molecular mechanisms of autophagy in the cardiovascular system. Circ Res. 2015;116:456-67.

5. Nussenzweig SC, Verma S, Finkel T. The role of autophagy in vascular biology Circ Res. 2015;116:480-8.

6. De Meyer GR, Grootaert MO, Michiels CF, Kurdi A, Schrijvers DM, Martinet W. Autophagy in vascular disease. Circ Res. 2015;116:468-79.

7. Frake RA, Ricketts T, Menzies FM, Rubinsztein DC. Autophagy and neurodegeneration. J Clin Invest. 2015;125:65-74.

8. Lavandero S, Chiong M, Rothermel BA, Hill JA. Autophagy in cardiovascular biology. J Clin Invest. 2015;125:55-64.

9. Fernández ÁF, López-Otín C. The functional and pathologic relevance of autophagy proteases. J Clin Invest. 2015;125:33-41.

10. Levine B, Packer M, Codogno P. Development of autophagy inducers in clinical medicine. J Clin Invest. 2015;125:14-24.

11. Deretic V, Kimura T, Timmins G, Moseley P, Chauhan S, Mandell M. Immunologic manifestations of autophagy. J Clin Invest. 2015;125:75-84.

12. Kroemer G. Autophagy: a druggable process that is deregulated in aging and human disease. J Clin Invest. 2015;125:1-4.

13. Jiang X, Overholtzer M, Thompson CB. Autophagy in cellular metabolism and cancer. J Clin Invest. 2015;125:47-54.

14. Vakifahmetoglu-Norberg H, Xia HG, Yuan J. Pharmacologic agents targeting autophagy. J Clin Invest. 2015;125:5-13.

15. Kim YC, Guan KL. mTOR: a pharmacologic target for autophagy regulation. $J$ Clin Invest. 2015;125:25-32.

16. Gottlieb RA, Andres AM, Sin J, Taylor DP. Untangling autophagy measurements: all fluxed up. Circ Res. 2015;116:504-14.

17. Orogo AM, Gustafsson $\AA$ B. Therapeutic targeting of autophagy: potential and concerns in treating cardiovascular disease. Circ Res. 2015;116:489-503.

18. Madeo F, Zimmermann A, Maiuri MC, Kroemer G. Essential role for autophagy in life span extension. $J$ Clin Invest. 2015;125:85-93.

19. Klionsky DJ. Autophagy revisited: a conversation with Christian de Duve. Autophagy. 2008;4:740-3

20. Yang Z, Klionsky DJ. Mammalian autophagy: core molecular machinery and signaling regulation. Curr Opin Cell Biol. 2010;22:124-31.

21. Ravikumar B, Sarkar S, Davies JE, Futter M, Garcia-Arencibia M, GreenThompson ZW, et al. Regulation of mammalian autophagy in physiology and pathophysiology. Physiol Rev. 2010;90:1383-435.

22. Komatsu M, Waguri S, Ueno T, Iwata J, Murata S, Tanida I, et al. Impairment of starvation-induced and constitutive autophagy in Atg7-deficient mice. J Cell Biol. 2005; 169:425-34

23. Mortensen M, Soilleux EJ, Djordjevic G, Tripp R, Lutteropp M, Sadighi-Akha E, et al. The autophagy protein Atg7 is essential for hematopoietic stem cell main tenance. J Exp Med. 2011;208:455-67.

24. Komatsu M, Waguri S, Chiba T, Murata S, Iwata J, Tanida I, et al. Loss of autophagy in the central nervous system causes neurodegeneration in mice. Nature. 2006;441:880-4.

25. Kaushik S, Rodriguez-Navarro JA, Arias E, Kiffin R, Sahu S, Schwartz GJ, et al Autophagy in hypothalamic AgRP neurons regulates food intake and energy balance. Cell Metab. 2011;14:173-83.

26. Hara T, Nakamura K, Matsui M, Yamamoto A, Nakahara Y, SuzukiMigishima R, et al. Suppression of basal autophagy in neural cells causes neurodegenerative disease in mice. Nature. 2006;441:885-9.

27. Masiero E, Agatea L, Mammucari C, Blaauw B, Loro E, Komatsu M, et al. Autophagy is required to maintain muscle mass. Cell Metab. 2009;10:507-15.

28. Quan W, Lim YM, Lee MS. Role of autophagy in diabetes and endoplasmic reticulum stress of pancreatic B-cells. Exp Mol Med. 2012;44:81-8.

29. Singh KK, Lovren F, Pan Y, Quan A, Ramadan A, Matkar PN, et al. The essential autophagy gene ATG7 modulates organ fibrosis via regulation of endothelial-tomesenchymal transition. J Biol Chem. 2015;290:2547-59. 
30. Torisu K, Singh KK, Torisu T, Lovren F, Liu J, Pan Y, et al. Intact endothelial autophagy is required to maintain vascular lipid homeostasis. Aging Cell. 2016;15:187-91.

31. Rajamäki K, Lappalainen J, Oörni K, Välimäki E, Matikainen S, Kovanen PT, et al. Cholesterol crystals activate the NLRP3 inflammasome in human macrophages: a novel link between cholesterol metabolism and inflammation. PLoS One. 2010;5:e11765.

32. Razani B, Feng C, Coleman T, Emanuel R, Wen H, Hwang S, et al. Autophagy links inflammasomes to atherosclerotic progression. Cell Metab. 2012;15:534-44.

33. Chen ML, Yi L, Jin X, Liang XY, Zhou Y, Zhang T, et al. Resveratrol attenuates vascular endothelial inflammation by inducing autophagy through the cAMP signaling pathway. Autophagy. 2013;9:2033-45.

34. Uberti F, Lattuada D, Morsanuto V, Nava U, Bolis G, Vacca G, et al. Vitamin D protects human endothelial cells from oxidative stress through the autophagic and survival pathways. J Clin Endocrinol Metab. 2014;99:1367-74.

35. Ouseph MM, Huang Y, Banerjee M, Joshi S, MacDonald L, Zhong Y, et al. Autophagy is induced upon platelet activation and is essential for hemostasis and thrombosis. Blood. 2015;126:1224-33.

36. Torisu T, Torisu K, Lee IH, Liu J, Malide D, Combs CA, et al. Autophagy regulates endothelial cell processing, maturation and secretion of von Willebrand factor. Nat Med. 2013;19:1281-7.

37. Reheman A, Gross P, Yang H, Chen P, Allen D, Leytin V, et al. Vitronectin stabilizes thrombi and vessel occlusion but plays a dual role in platelet aggregation. J Thromb Haemost. 2005;3:875-83.

38. Reheman A, Yang H, Zhu G, Jin W, He F, Spring CM, et al. Plasma fibronectin depletion enhances platelet aggregation and thrombus formation in mice lacking fibrinogen and von Willebrand factor. Blood. 2009;113:1809-17.

39. Wang Y, Reheman A, Spring CM, Kalantari J, Marshall AH, Wolberg AS, et al. Plasma fibronectin supports hemostasis and regulates thrombosis. J Clin Invest. 2014:124:4281-93.

40. Singh KK, Yanagawa B, Quan A, Wang R, Garg A, Khan R, et al. Autophagy gene fingerprint in human ischemia and reperfusion. J Thorac Cardiovasc Surg. 2014;147:1065-72.e1.

41. Yau JW, Teoh H, Verma S. Endothelial cell control of thrombosis. BMC Cardiovasc Disord. 2015;15:130.
42. Kretz CA, Vaezzadeh N, Gross PL. Tissue factor and thrombosis models. Arte rioscler Thromb Vasc Biol. 2010;30:900-8.

43. Ming XF, Rajapakse AG, Carvas JM, Ruffieux J, Yang Z. Opposing and uncou pling effects of $\mathrm{mTOR}$ and $\mathrm{S} 6 \mathrm{~K} 1$ in the regulation of endothelial tissue facto expression. FEBS Lett. 2010;584:135-40.

44. Chen KD, Wang CC, Tsai MC, Wu CH, Yang HJ, Chen LY, et al. Interconnections between autophagy and the coagulation cascade in hepatocellular carcinoma. Cell Death Dis. 2014;5:e1244.

45. Kambas K, Mitroulis I, Apostolidou E, Girod A, Chrysanthopoulou A, Pneumatikos I, et al. Autophagy mediates the delivery of thrombogenic tissue factor to neutrophil extracellular traps in human sepsis. PLoS One. 2012;7:e45427.

46. Ruf W, Riewald M. Regulation of tissue factor expression. Madame Curie Bioscience Database. Available at: https://www.ncbi.nlm.nih.gov/books/ NBK6620/. Accessed March 21, 2017.

47. Lüscher TF, Steffel J, Eberli FR, Joner M, Nakazawa G, Tanner FC, et al. Drugeluting stent and coronary thrombosis: biological mechanisms and clinical impli cations. Circulation. 2007:115:1051-8.

48. Barilli A, Visigalli R, Sala R, Gazzola GC, Parolari A, Tremoli E, et al. In human endothelial cells rapamycin causes mTORC 2 inhibition and impairs cell viability and function. Cardiovasc Res. 2008;78:563-71.

49. Camici GG, Steffel J, Amanovic I, Breitenstein A, Baldinger J, Keller S, et al Rapamycin promotes arterial thrombosis in vivo: implications for everolimus and zotarolimus eluting stents. Eur Heart J. 2010;31:236-42.

50. Steffel J, Latini RA, Akhmedov A, Zimmermann D, Zimmerling P, Lüscher TF, et al. Rapamycin, but not FK-506, increases endothelial tissue factor expression: implications for drug-eluting stent design. Circulation. 2005;112:2002-11.

51. Nishida Y, Arakawa S, Fujitani K, Yamaguchi H, Mizuta T, Kanaseki T, et al. Discovery of Atg5/Atg7-independent alternative macroautophagy. Nature. 2009;461:654-8.

52. Kuma A, Hatano M, Matsui M, Yamamoto A, Nakaya H, Yoshimori T, et al. The role of autophagy during the early neonatal starvation period. Nature. 2004;432 1032-6.

Key Words: ATG7, autophagy, thrombosis 
TABLE E1. Primers used to perform qPCR for human (Homo sapiens) and mouse (Mus musculus) genes

\begin{tabular}{llll}
\hline Species & Gene target & Forward/reverse & Sequence \\
\hline Human & ATG7 & Forward & $5^{\prime}$-ATTGCTGCATCAAGAAACCC-3' \\
Human & ATG7 & Reverse & $5^{\prime}$-GATGGAGAGCTCCTCAGCA-3' \\
Human & TF & Forward & $5^{\prime}$-TCCCCAGAGTTCACACCTTACC-3' \\
Human & TF & Reverse & $5^{\prime}$-CCTTTCTCCTGGCCCATACAC-3' \\
Human & GAPDH & Forward & $5^{\prime}$-CACCAGGGCTGCTTTTAACTCTGGTA-3' \\
Human & GAPDH & Reverse & $5^{\prime}$-CCTTGACGGTGCCATGGAATTTGC-3' \\
Mouse & ATG7 & Forward & $5^{\prime}$-TGGCTGCTACTTCTGCAATGATGT-3' \\
Mouse & ATG7 & Reverse & Ex14R: $5^{\prime}$-GGTCCAGAGTCCGGTCTCTGG-3' \\
Mouse & & & ${\text { In13R4: } 5^{\prime} \text {-GCAAGCTCACTAGGCTGCAGAACC-3' }}^{\prime}$ \\
Mouse & TF & Forward & $5^{\prime}$-TCAAGCACGGGAAAGAAAAC-3' \\
Mouse & TF & Reverse & $5^{\prime}$-CTGCTTCCTGGGCTATTTTG-3' \\
Mouse & GAPDH & Forward & $5^{\prime}$-TGGATGCAGGGATGATGTTCT-3' \\
\hline
\end{tabular}

ATG7, Autophagy-related 7; $T F$, tissue factor; GAPGH, glyceraldehyde 3-phosphate dehydrogenase. 